\title{
Infection with high proportion of multidrug-resistant bacteria in conflict- related injuries is associated with poor outcomes and excess resource consumption: a cohort study of Syrian patients treated in Jordan
}

Andreas Älgå ${ }^{1,6^{*}}$ (D), Sidney Wong ${ }^{2}$, Muhammad Shoaib ${ }^{3}$, Kalle Lundgren ${ }^{4}$, Christian G. Giske ${ }^{5}$, Johan von Schreeb ${ }^{6}$ and Jonas Malmstedt ${ }^{1}$

\begin{abstract}
Background: Armed conflicts are a major contributor to injury and death globally. Conflict-related injuries are associated with a high risk of wound infection, but it is unknown to what extent infection directly relates to sustainment of life and restoration of function. The aim of this study was to investigate the outcome and resource consumption among civilians receiving acute surgical treatment due to conflict-related injuries. Patients with and without wound infections were compared.

Methods: We performed a cohort study using routinely collected data from 457 consecutive Syrian civilians that received surgical treatment for acute conflict-related injuries during 2014-2016 at a Jordanian hospital supported by Médecins Sans Frontières. We defined wound infection as clinical signs of infection verified by a positive culture. We used logistic regression models to evaluate infection-related differences in outcome and resource consumption.

Results: Wound infection was verified in 49/457 (11\%) patients. Multidrug-resistance (MDR) was detected in 36/49 (73\%) of patients with infection. Among patients with infection, 11/49 (22\%) were amputated, compared to 37/408 (9\%) without infection, crude relative risk = 2.62 (95\% confidence interval 1.42-4.81). Infected patients needed 12 surgeries on average, compared to five in non-infected patients $(p<.00001)$. Mean length of stay was 77 days for patients with infection, and 35 days for patients without infection ( $p=.000001)$.
\end{abstract}

Conclusions: Among Syrian civilians, infected conflict-related wounds had a high prevalence of MDR bacteria. Wound infection was associated with poor outcomes and high resource consumption. These results could guide the development of antibiotic protocols and adaptations of surgical management to improve care for wound infections in conflict-related injuries.

Trial registration: ClinicalTrials.gov (NCT02744144). Registered April 13, 2016. Retrospectively registered.

Keywords: Refugee, War wounds, Wound infection, Multidrug-resistance, Resource limited setting

\footnotetext{
* Correspondence: andreas.alga@ki.se

'Department of Clinical Science and Education, Södersjukhuset, Karolinska

Institutet, Stockholm, Sweden

${ }^{6}$ Department of Public Health Sciences, Karolinska Institutet, Stockholm,

Sweden

Full list of author information is available at the end of the article
}

(c) The Author(s). 2018 Open Access This article is distributed under the terms of the Creative Commons Attribution 4.0 International License (http://creativecommons.org/licenses/by/4.0/), which permits unrestricted use, distribution, and reproduction in any medium, provided you give appropriate credit to the original author(s) and the source, provide a link to the Creative Commons license, and indicate if changes were made. The Creative Commons Public Domain Dedication waiver (http://creativecommons.org/publicdomain/zero/1.0/) applies to the data made available in this article, unless otherwise stated. 


\section{Background}

Worldwide, armed conflicts are a major contributor to the global burden of disease [1]. Conflict-related injuries often result in soft tissue and bone being contaminated with foreign material, leading to infection [2, 3]. The cornerstones of war wound management are surgical intervention and antibiotic therapy. Surgical interventions, mainly debridement of devitalized or infected tissue, are performed according to treatment principles for traumatic wounds [4]. Antibiotic therapy is utilised both as perioperative prophylaxis and as part of the treatment of wound infections $[4,5]$. However, the increasing rate of antibiotic resistance globally [6], primarily owing to the over- and misuse of antibiotics [5, 7] threatens the effectiveness of available antibiotics. Retrospective reports of injured military combatants are the main source for knowledge about treatment efficacy in traumatic wounds $[8,9]$. These results may not be applicable to a civilian setting due to the military use of ballistic protection and forward surgical teams. It is therefore unknown if wound infection itself threatens life and restoration of function for injured civilians.

Furthermore, it is unknown to what extent acute conflict-related wound infections are caused by multidrug-resistant (MDR) organisms. High incidence of MDR organisms in civilians has been shown in the Middle East, but reports generally are either based on culture results from chronic wounds $[10,11]$ or on all available culture samples, not limited to patients with clinical signs of infection [12, 13]. We had the unique opportunity to study cultures strictly obtained in the presence of clinical signs of wound infection in civilians with acute conflict-related injuries. The research on this patient group is limited. We aimed to assess MDR incidence and compare the outcome and resource consumption for acute conflict-related injuries, with and without wound infection in civilian patients receiving surgery. We hypothesised that infections negatively affect patient outcomes and lead to an increased burden of care.

\section{Methods}

\section{Study setting}

The Syrian armed conflict broke out in 2011 and quickly deteriorated, claiming $40 \%$ of all global war fatalities by 2012 [14]. Médecins Sans Frontières/Doctors Without Borders (MSF) runs an emergency trauma project at the Ministry of Health hospital in Ar Ramtha, Jordan, five kilometres from the Syrian border [15]. At this facility patients from the Syrian armed conflict receive treatment for blast and gunshot injuries. Wounds are treated according to guidelines based on the International Committee of the Red Cross (ICRC) war surgery protocol [4]. As adjunct to surgical wound debridement, all patients receive prophylactic treatment for $48-72 \mathrm{~h}$ with narrow-spectrum antibiotic agents (Cefazolin or Ampicillin). Metronidazole is added for patients with complicated open fractures, perforated viscous at laparotomy or penetrating craniocerebral wounds. Acute war wounds are left open following the first surgery. After 3-5 days, wounds are assessed and treated by delayed primary closure if possible.

\section{Study design and participants}

We performed an open cohort study with longitudinal data collection. We used routinely collected clinical data from consecutive patients admitted due to acute conflict-related injuries. Availability of standardized culture results determined the start of the study (September 17, 2014), and closure of the Syrian border determined the end (June 21, 2016). The cohort included all patients that received surgical treatment for conflict-related wounds. Surgeons obtained intraoperative tissue samples (bone, soft tissue, or fluid) only if the wounds showed clinical signs of infection. An accredited clinical microbiology laboratory (King Abdullah University Hospital, Ar Ramtha) performed culture and antibiotic susceptibility testing. Main culture media were blood, chocolate, and MacConkey agar. Species were identified through manual flowcharts or automated Vitek 2 technology (bioMérieux, Marcy l'Etoile, France). Antibiotic resistance was determined by manual disk diffusion (Bio-Rad, Hercules, California, USA) or automated using Vitek 2 technology, and interpreted according to the guidelines from the Clinical and Laboratory Standards Institute [16]. We defined clinical signs of infection as purulent discharge $[17,18]$ or foul smell, in accordance to locally established clinical routines. The diagnosis of wound infection required both clinical signs of infection and at least one positive culture.

Paper-based patient files provided information on vital signs at hospital admission. We calculated coded Revised Trauma Score (RTSc) [19] from respiratory rate, systolic blood pressure, and Glasgow Coma Scale [20] in a subsample consisting of all patients with infection (cases) with one non-infected control matched for age and sex. Mean RTSc in cases was then compared to controls to investigate possible confounding by patients with infection having sustained a more severe trauma compared to those without.

The clinical patient database provided demographic information, admission dates, diagnoses and details of performed surgeries. Wound culture reports provided details of bacterial species and their resistance patterns. We defined MDR as resistance to at least one antibiotic from three or more relevant antibiotic groups [21]. We considered methicillin-resistant Staphylococcus aureus (MRSA) as MDR. 
The distinction between combatants and civilians is complex, particularly in internal armed conflicts [22]. Since our aim was to study non-military injuries, we defined civilians as patients without protective equipment, such as body armour or helmets, and without assistance by forward surgical teams.

\section{Outcomes}

The outcome measures were in-hospital death, limb amputations and resource consumption (number of surgeries, length of hospitalization).

\section{Statistical analysis}

We used the Epidata entry software (The Epidata Association, Odense, Denmark) to collect paper-based clinical, and microbiology data, and performed all analyses using SPSS Statistics (IBM Corp., Armonk, NY, USA). We used mean with standard deviation (SD) for summarizing scale variables, and proportions with $95 \%$ confidence intervals $(95 \% \mathrm{CI})$ for categorical variables. We conducted bivariate analyses with Chi-square to compare two categorical variables, and t-test to compare scale variables. We used binary logistic regression models to evaluate differences in outcome and resource consumption between patients with and without infections. We considered $p$-values $<.05$ significant.

\section{Role of the funding source}

The funders of the study had no role in study design, data collection, data analysis, data interpretation, or writing of the report. Authors had access to the raw data in the study, and had final responsibility for the decision to submit for publication.

\section{Results}

The cohort consisted of 457, predominantly male (86\%) individuals with a mean age of 27 years (95\% CI 25-28) (Table 1). Clinical signs of infection were found in $81 / 457$ (18\%) patients. Wound infection was verified with at least one positive culture in 49/81 (60\%) patients, corresponding to a wound infection rate of $11 \%$ (49/457). During the study period 37/457 (8\%) patients died in hospital and 48/ $457(11 \%)$ patients had a major amputation.

MDR was detected in 36/49 (73\%) of patients with positive wound cultures. Mean time to detection of MDR bacteria was 16.5 (IQR 8-30) days after hospital admission. The most common bacteria were Staphylococcus aureus (15/49) (73\% MRSA), Pseudomonas (12/ 49) (17\% MDR), Klebsiella pneumoniae (11/49) (82\% MDR), Enterobacter (9/49) (78\% MDR), E. coli (8/49) (100\% MDR), Proteus (8/49) (63\% MDR), and Acinetobacter (5/49) (100\% MDR). The K. pneumoniae, Enterobacter, and $E$. coli strains were resistant to most
Table 1 Characteristics of 457 consecutive patients that received surgical treatment due to conflict-related injuries

\begin{tabular}{lll}
\hline Characteristic & & \\
\hline Age in years at hospital admission, mean $(95 \% \mathrm{Cl})$ & 27 & $(25-28)$ \\
Male, $\mathrm{n}(\%)$ & 395 & $(86)$ \\
Discharged, n (\%) & 198 & $(43)$ \\
Defaulter, n (\%) & 23 & $(5)$ \\
Referred to other structure, n (\%) & 199 & $(44)$ \\
Death, n (\%) & 37 & $(8)$ \\
Number of readmissions, $\mathrm{n}(\%)$ & & \\
0 & 400 & $(88)$ \\
1 & 45 & $(10)$ \\
2 & 10 & $(2)$ \\
3 & 2 & $(0)$ \\
\hline
\end{tabular}

antimicrobials, but remained susceptible to carbapenems. Most of the Acinetobacter strains were also resistant to carbapenems.

Mean RTSc was similar in matched patients with (7.31, SD 0.67) and without (7.33, SD 1.18) infection, indicating that patients with infection were not more severely injured than patients without infection. The most common surgical procedure was debridement of tissue (39\%), followed by laparotomy (11\%), and external fixation of fracture (10\%) (Table 2).

\section{Death}

Of patients with infection $2 / 49$ (4\%) died, compared to $35 / 408$ (9\%) of patients without infection, crude relative risk $=0.48$ (95\% CI 0.12-1.92) (Table 3). The two patients with infection that died did so after 40 and 49 days; whereas patients without infection died after a median

Table 2 Number and type of primary procedure

\begin{tabular}{ll}
\hline Type of primary procedure & $\mathrm{n}(\%)$ \\
\hline Debridement of tissue & $180(39)$ \\
Laparotomy & $49(11)$ \\
External fixation of fracture & $47(10)$ \\
Wound closure & $33(7)$ \\
Vascular repair & $31(7)$ \\
Amputation & $25(5)$ \\
Other orthopaedic procedure & $21(5)$ \\
Chest procedure & $19(4)$ \\
Other surgical intervention & $17(4)$ \\
Bowel repair & $16(4)$ \\
Skin graft & $12(3)$ \\
K-wire manipulation & $4(1)$ \\
Solid organ management & $3(1)$ \\
Total & $457(100)$ \\
\hline
\end{tabular}


Table 3 Outcomes in patients with and without wound infection

\begin{tabular}{|c|c|c|c|c|c|}
\hline \multirow{2}{*}{$\begin{array}{l}\text { Outcome } \\
\text { Amputation, } \\
n(\%)\end{array}$} & \multicolumn{2}{|c|}{$\begin{array}{l}\text { With infection } \\
(n=49)\end{array}$} & \multicolumn{2}{|c|}{$\begin{array}{l}\text { Without infection } \\
(n=408)\end{array}$} & \multirow{2}{*}{$\begin{array}{l}p \\
.007^{\mathrm{a}}\end{array}$} \\
\hline & 11 & (22) & 37 & (9) & \\
\hline Death, n (\%) & 2 & (4) & 35 & (9) & $.407^{\mathrm{a}}$ \\
\hline $\begin{array}{l}\text { Amputation or death, } \\
n(\%)\end{array}$ & 11 & (22) & 66 & (16) & $.311^{\mathrm{a}}$ \\
\hline $\begin{array}{l}\text { Days in hospital, } \\
\text { mean (SD) }\end{array}$ & 77 & (50) & 35 & (39) & $<.0001^{\mathrm{b}}$ \\
\hline $\begin{array}{l}\text { Number of surgical } \\
\text { procedures, mean } \\
\text { (SD) }\end{array}$ & 12 & (9) & 5 & (5) & $<.0001^{b}$ \\
\hline $\begin{array}{l}\text { Major surgical } \\
\text { procedures, mean (SD) }\end{array}$ & 11 & (7) & 4 & (4) & $<.0001^{\mathrm{b}}$ \\
\hline
\end{tabular}

time of 5 (IQR 2-14) days. Of patients with MDR infection $2 / 36(6 \%)$ died, compared to $0 / 13(0 \%)$ of patients with non-MDR infection.

\section{Amputation}

Patients with infection had a higher amputation rate (22\%), compared to patients without infection (9\%) (Table 3), crude relative risk 2.62 (95\% CI 1.42-4.81). Patients with MDR infection had a slightly higher risk for amputation than patients with non-MDR infection, although non-significant (9/36 (25\%) compared to $2 / 13$ (15\%), relative risk 1.83 (95\% CI 0.34-9.89)).

\section{Resource consumption}

The average numbers of procedures per patient were six (95\% CI 1-47). Patients with infection needed 12 surgeries on average, compared to five in patients without infection (Table 3). Patients with MDR infection needed 13 surgeries on average, compared to 11 in patients with non-MDR infection $(p=.690)$.

Mean length of stay was longer for patients with infection (77 days), compared to patients without infection (35 days), $(p<.000001)$. Mean length of stay was 69 days for patients with MDR infection, and 99 days for patients with non-MDR infection $(p=.131)$.

\section{Multivariate analysis}

The increased risk for amputation in patients with infection remained after adjustment for sex and age, odds ratio $3.0,95 \%$ CI $1.40-6.43(p=.005)$.

\section{Discussion}

Wound infection was associated with poor outcomes and high resource consumption in this cohort of Syrian civilians who had surgery for acute conflict-related injuries. We reduced the risk for misclassification by using appropriate criteria for wound infection, i.e. clinical signs of infection verified by a least one positive tissue culture. To our knowledge, this is the first large cohort study investigating the association between wound infection and outcome and resource consumption in civilians with conflict-related injuries.

Patients with infection needed more surgeries, including amputations, compared to those without. Previous research on military combatants with open tibia fractures have found infection to be significantly associated with both amputation and need for surgery [23], while another study on military combatants was not able to show this association [24]. The average number of surgeries in the present study was six (12 for infected wounds), which highlights the complexity of care. The ICRC war surgical manual suggests that more than two surgeries denote a complication [4]. Our study results contradict this low "benchmark" number. Moreover, mean length of stay was longer for patients with infection compared to patients without infection, which is in concordance with previous results from both military [23] and civilian settings [25].

We found an unexpectedly high occurrence of MDR organisms in acutely injured civilians with wound infection (73\%). Since MDR infection tends to develop over time, we expected lower MDR levels than those of previous reports of Syrian civilians with non-acute conflict-related injuries in Jordan $(69 \%)$ and Israel $(59 \%)$ [11, 12]. A high prevalence of MDR bacterial colonization has also been shown when screening conflict-injured civilians in Libya [26], as well as after having fled to Europe (59\%) [27]. MDR bacteria, particularly those forming biofilm, has been identified as a significant risk factor for persistent infection in patients with conflict-related wounds [28]. Since patients in our study were not screened for MDR bacteria it is difficult to determine whether they were colonized at admission or acquired MDR bacteria during hospitalization. Our results suggest an association between MDR infection and amputation, however non-significant. This lack of significance could be due to the high incidence of MDR infection. This is supported by results from a study with a lower MDR incidence (32\%), where only $2 \%$ were amputated [29].

The high prevalence of MDR in Syrian civilians may be partly explained by a wide availability of over-the-counter antibiotics in Syria prior to the armed conflict [30]. Colonization of the patients themselves and healthcare-associated infections have been suggested as the main source for conflict-related wound infections by MDR organisms [31]. Simultaneously, it is crucial to distinguish infection from colonization to limit the use of broad-spectrum antibiotics, since excessive use may lead to further development of MDR organisms [32].

Knowledge on the likelihood of, or presence of, infection in wounds treated in conflict-related settings may potentially lead to alterations of protocol. According to 
the commonly used ICRC regimen, wounds are debrided surgically and a narrow spectrum antibiotic agent is supplied at the time of debridement. Our results show that presence of infection is associated with prolonged hospitalization, indicating that debridement was not curative in most infected patients. The high prevalence of MDR bacteria suggests that routine narrow spectrum prophylaxis may be insufficient in settings similar to that at Ar Ramtha Hospital, Jordan. Additionally, routine use of narrow spectrum antibiotics could contribute to an increase of MDR, which suggests a need for caution in a setting where three of four patients with wound infections are infected by MDR bacteria.

Our results should be interpreted taking into consideration some limitations. First, the dependence upon routine data limited the number of parameters available for control of confounding. We lacked details on comorbidities relevant for wound healing. However, with the cohort mean age of 27, chronic diseases, such as type 2 diabetes, are likely to be rare. Second, it is difficult to exclude that some cultures were collected from patients with limited clinical signs of infection. Local treatment guidelines state that cultures should only be obtained from wounds with clinical signs of infection. We performed semi-structured interviews with the treating physicians and found satisfactory adherence to these guidelines (data not yet published). Third, we risk underestimating the frequencies of wound infection with our strict definition, requiring both clinical signs and at least one positive culture. However, the risk of bias is thought to be low, as under-diagnosis of infection probably is non-differential and therefore not related to outcome. The major limitation is the lack of detailed information on injury severity. Although we calculated RTSc scores for each clinically infected patient and for matched non-infected patients and found no significant difference between the two groups, we lack anatomical and wound-specific details, such as localisation and extent of injury. We cannot exclude that such parameters differ between infected and non-infected patients. Strengths of the study include the prospective approach, a large cohort of consecutive civilian patients with acute conflict-related injuries, the clear distinction that cultures originate from patients with a clinically detected wound infection, intraoperative tissue sampling for culture and the use of an accredited microbiology laboratory.

\section{Conclusions}

Wound infection is associated with poor outcomes and high resource consumption in Syrian civilians with conflict-related injuries. Patients with infection needed more surgeries, underwent more amputations, and were hospitalized longer, compared to those without infection. In addition, we found a high occurrence of MDR organisms in patients with infected conflict-related wounds. Our results could increase the understanding of context-specific MDR patterns, and aid the development of antibiotic and surgical protocols. These actions could potentially help clinicians to reduce serious wound infections and decrease morbidity. Future research is needed to prove that the association between wound infection and outcome represents causality. We urge for more studies to define what is an acceptable re-operation rate in a conflict setting.

\section{Abbreviations \\ Cl: Confidence interval; ICRC: International Committee of the Red Cross; MDR: Multidrug-resistance; MRSA: Methicillin-resistant Staphylococcus aureus; MSF: Médecins Sans Frontières/Doctors Without Borders; RTSc: Revised Trauma Score, coded; SD: Standard deviation}

\section{Acknowledgements}

We thank the MSF Sweden Innovation Unit and the MSF teams in Amman and in Ar Ramtha for facilitating this research. We thank Hezha Seradji for assistance in data collection and data entry, and Dr. Mohammad Abdulhamid Alqudah, chairperson at the Pathology and microbiology department at King Abdullah University Hospital for their support.

\section{Funding}

This work was supported by grants from the Stockholm County Council (ALF) and from the Swedish National Board of Health and Welfare.

\section{Availability of data and materials}

The data that support the findings of this study are available from MSF but restrictions apply to the availability of these data, which were used under license for the current study, and so are not publicly available. Data are however available from the authors upon reasonable request and with permission of MSF. As the data originate from a clinical data set it was not possible to obtain consent for publication of individual patient data.

\section{Authors' contributions}

$A \ddot{A}, J M, J v S, K L$ and SW designed the study. MS made substantial contributions to acquisition of data. Ä̈ and JM analysed the data. Ä̈ wrote the first draft. JM, JVS, KL, SW, MS and CG were major contributors in revising the manuscript critically for important intellectual content. All authors read and approved the final manuscript and agreed to be accountable for all aspects of the work in ensuring that questions related to the accuracy or integrity of any part of the work are appropriately investigated and resolved.

Ethics approval and consent to participate

This study was performed in accordance with the Declaration of Helsinki and approved by the Ethics Review Committee of Jordan Ministry of Health (MOH REC 150037) and the Ethics Review Board of MSF International (www.msf.org/en/msf-ethics-review-board) (ID 1520). The need for written consent to participate in this study was formally waived by the ethics committees.

\section{Competing interests}

The authors declare that they have no competing interests.

\section{Publisher's Note}

Springer Nature remains neutral with regard to jurisdictional claims in published maps and institutional affiliations.

\section{Author details}

'Department of Clinical Science and Education, Södersjukhuset, Karolinska Institutet, Stockholm, Sweden. ${ }^{2}$ Médecins Sans Frontières, Operational Centre Amsterdam, Amsterdam, The Netherlands. ${ }^{3}$ Médecins Sans Frontières, Amman, Jordan. ${ }^{4}$ Department of Molecular Medicine and Surgery, Karolinska Institutet and Karolinska University Hospital, Stockholm, Sweden. ${ }^{5}$ Division of Clinical Microbiology, Department of Laboratory Medicine, Karolinska Institutet and Karolinska University Hospital, Stockholm, Sweden.

${ }^{6}$ Department of Public Health Sciences, Karolinska Institutet, Stockholm, Sweden. 
Received: 22 September 2017 Accepted: 15 May 2018

Published online: 22 May 2018

\section{References}

1. Murray CJ, King G, Lopez AD, Tomijima N, Krug EG. Armed conflict as a public health problem. BMJ. 2002;324(7333):346-9.

2. Fares Y, El-Zaatari M, Fares J, Bedrosian N, Yared N. Trauma-related infections due to cluster munitions. J Infect Public Health. 2013;6(6):482-6.

3. Blyth DM, Yun HC, Tribble DR, Murray CK. Lessons of war: combat-related injury infections during the Vietnam war and operation Iraqi and enduring freedom. J Trauma Acute Care Surg. 2015;79(Suppl 2):S227-35.

4. Giannou C, Baldan M. War surgery: working with limited resources in armed conflict and other situations of violence. Geneva: International Committee of the Red Cross, Switzerland; 2010.

5. Sahli ZT, Bizri AR, Abu-Sittah GS. Microbiology and risk factors associated with war-related wound infections in the Middle East. Epidemiol Infect. 2016;144(13):2848-57.

6. World Health Organization. Antimicrobial resistance: 2014 global report on surveillance. Geneva: World Health Organization; 2014.

7. Odonkor ST, Addo KK. Bacteria resistance to antibiotics: recent trends and challenges. Int J Biol Med Res. 2011;2(4):1204-10

8. Murray CK, Obremskey WT, Hsu JR, Andersen RC, Calhoun JH, Clasper JC, et al. Prevention of infections associated with combat-related extremity injuries. J Trauma. 2011;71 Suppl 2:S235-57.

9. Hospenthal DR, Murray CK, Andersen RC, Bell RB, Calhoun JH, Cancio LC, et al. Guidelines for the prevention of infections associated with combat-related injuries: 2011 update: endorsed by the Infectious Diseases Society of America and the surgical infection society. J Trauma. 2011;71(Suppl 2):S210-34.

10. Murphy RA, Ronat JB, Fakhri RM, Herard P, Blackwell N, Abgrall S, et al. Multidrug-resistant chronic osteomyelitis complicating war injury in Iraq civilians. J Trauma. 2011;71(1):252-4.

11. Teicher CL, Ronat JB, Fakhri RM, Basel M, Labar AS, Herard P, et al. Antimicrobial drug-resistant bacteria isolated from Syrian war-injured patients, august 2011-march 2013. Emerg Infect Dis. 2014;20(11):1949-51.

12. Peretz A, Labay K, Zonis Z, Glikman D. Disengagement does not apply to bacteria: a high carriage rate of antibiotic-resistant pathogens among Syrian civilians treated in israeli hospitals. Clin Infect Dis. 2014;59(5):753-4.

13. Sutter DE, Bradshaw LU, Simkins LH, Summers AM, Atha M, Elwood RL, et al. High incidence of multidrug-resistant gram-negative bacteria recovered from afghan patients at a deployed US military hospital. Infect Control Hosp Epidemiol. 2011;32(9):854-60

14. The University of Uppsala Conflict Data Program. 2017. http://ucdp.uu.se/ \#country/652. Accessed 15 May 2017.

15. Doctors without Borders MSF USA. 2017. http://www. doctorswithoutborders.org/country-region/jordan. Accessed 15 May 2017.

16. Wayne PA. Clinical and Laboratory Standards Institute (CLSI) Method for Dilution Antimicrobial Susceptibility Tests for Bacteria that Grow Aerobically. Approved standard-8th ed, CLSI document M07-A8, USA; 2009.

17. Horan TC, Gaynes RP, Martone WJ, Jarvis WR, Emori TG. CDC definitions of nosocomial surgical site infections, 1992: a modification of CDC definitions of surgical wound infections. Am J Infect Control. 1992;20(5):271-4.

18. Wilson JA, Ward VP, Coello R, Charlett A, Pearson A. A user evaluation of the nosocomial infection National Surveillance System: surgical site infection module. J Hosp Infect. 2002;52(2):114-21.

19. Champion HR, Sacco WJ, Copes WS, Gann DS, Gennarelli TA, Flanagan ME. A revision of the trauma score. J Trauma. 1989;29(5):623-9.

20. Teasdale G, Jennett B. Assessment of coma and impaired consciousness. A practical scale. Lancet. 1974;2(7872):81-4.

21. Magiorakos AP, Srinivasan A, Carey RB, Carmeli Y, Falagas ME, Giske CG, et al. Multidrug-resistant, extensively drug-resistant and pandrug-resistant bacteria: an international expert proposal for interim standard definitions for acquired resistance. Clin Microbiol Infect. 2012;18(3):268-81.

22. Wasznik C. Protection of civilians under international humanitarian law: trends and challenges. NOREF report. 2011. https://www.regjeringen.no/ globalassets/upload/ud/vedlegg/hum/reclaiming_background.pdf. Accessed 1 Apr 2017.

23. Burns TC, Stinner DJ, Mack AW, Potter BK, Beer R, Eckel T, et al. Microbiology and injury characteristics in severe open tibia fractures from combat. J Trauma Acute Care Surg. 2012;72(4):1062-7.
24. Napierala MA, Rivera JC, Burns TC, Murray CK, Wenke JC, Hsu JR, et al. Infection reduces return-to-duty rates for soldiers with type III open tibia fractures. J Trauma Acute Care Surg. 2014;77(Suppl 2):S194-7.

25. Jimenez CM, Polo J, Espana JA. Risk factors for intracranial infection secondary to penetrating craniocerebral gunshot wounds in civilian practice. World Neurosurg. 2013;79(5-6):749-55.

26. Dau AA, Tloba S, Daw MA. Characterization of wound infections among patients injured during the 2011 Libyan conflict. East Mediterr Health J. 2013;19(4):356-61.

27. Koole K, Ellerbroek PM, Lagendijk R, Leenen LP, Ekkelenkamp MB. Colonization of Libyan civil war casualties with multidrug-resistant bacteria. Clin Microbiol Infect. 2013;19(7):E285-7.

28. Akers KS, Mende K, Cheatle KA, Zera WC, Yu X, Beckius ML, et al. Biofilms and persistent wound infections in United States military trauma patients: a case-control analysis. BMC Infect Dis. 2014;14:190.

29. Murphy RA, Okoli O, Essien I, Teicher C, Elder G, Pena J, Ronat JB, Bernabe KJ. Multidrug-resistant surgical site infections in a humanitarian surgery project. Epidemiol Infect. 2016:1-7.

30. Al-Faham Z, Habboub G, Takriti F. The sale of antibiotics without prescription in pharmacies in Damascus, Syria. J Infect Dev Ctries. 2011;5(5): $396-9$.

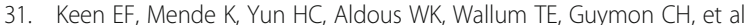
Evaluation of potential environmental contamination sources for the presence of multidrug-resistant bacteria linked to wound infections in combat casualties. Infect Control Hosp Epidemiol. 2012;33(9):905-11.

32. Eardley WG, Brown KV, Bonner TJ, Green AD, Clasper JC. Infection in conflict wounded. Philos Trans R Soc Lond Ser B Biol Sci. 2011;366(1562):204-18.

\section{Ready to submit your research? Choose BMC and benefit from:}

- fast, convenient online submission

- thorough peer review by experienced researchers in your field

- rapid publication on acceptance

- support for research data, including large and complex data types

- gold Open Access which fosters wider collaboration and increased citations

- maximum visibility for your research: over $100 \mathrm{M}$ website views per year

At BMC, research is always in progress.

Learn more biomedcentral.com/submissions 